\title{
AVALIAÇÃo DA POTENCIALIDAdE FISIOLÓGICA DE SEMENTES DE MARACUJÁ- DOCE (Passiflora alata Dryander) SUBMETIDAS AO ARMAZENAMENTO ${ }^{1}$
}

\author{
ELISETE APARECIDA FERNANDES OSIPI ${ }^{2} \&$ JOÃO NAKAGAWA ${ }^{3}$
}

\begin{abstract}
RESUMO- Averiguou-se a influência de três condições ambientais na capacidade de armazenamento da semente do maracujá-doce (Passiflora alata Dryander): ambiente não controlado (embaladas em saco de papel), câmara seca (embaladas em saco de papel) e câmara fria (embaladas em saco de polietileno). Nesses tratamentos, avaliaram-se o teor de água e as porcentagens de germinação, de plântulas anormais, de sementes dormentes e a de mortas, no decorrer de seis meses e após um ano. A germinação não diferiu entre os ambientes de conservação durante os seis meses iniciais de armazenamento. Após doze meses, contudo, a conservação favoreceu as sementes com grau de umidade próximo a 10\%, embaladas em sacos de polietileno e mantidas a $10^{\circ} \mathrm{C}$.
\end{abstract}

Termos para indexação: Passiflora alata, maracujá, sementes, germinação, armazenamento.

\section{EVALUATION OF PHYSIOLOGICAL POTENTIALITY OF SWEET PASSION-FRUIT SEEDS (Passiflora alata Dryander) SUBMITTED TO STORAGE}

\begin{abstract}
It was studied the influence of three environment conditions on storage capacity of sweet passion-fruit (Passiflora alata Dryander) seeds: not controled ambient (in paper bags), dry chamber ( in paper bags) and cold chamber (in plastic bags). It was evaluated water contents and germination percentage, abnormal seedlings, dormancy and died seeds, during six months and after one year. Germination has no difference among conservation ambients during the initial six months of storage. After twelve months, however, seeds with humidity close to $10 \%$ and aconditioned in plastic bags, showed better conservation, when maintained at $10^{\circ} \mathrm{C}$.
\end{abstract}

Index terms: Passiflora alata, passion-fruit, seeds, germination, storage.

\section{INTRODUÇÃO}

A propagação do maracujazeiro no Brasil é, predominantemente, sexuada e, dessa maneira, o armazenamento das sementes participa do processo produtivo de suas espécies. A esse respeito, tem sido a espécie Passiflora edulis Sims f. flavicarpa Deg (maracujá-amarelo) mais pesquisada, havendo indicações de que a manutenção da germinação é favorecida em ambientes controlados (Geraldi Júnior, 1974; Thai, 1977; Almeida, 1985; Nakagawa et al., 1991; Fonseca, 2004) e voltados à conservação de sementes ortodoxas (Becwer et al.,1983).

Em relação às sementes do maracujá-doce (Passiflora alata Dryander), apesar da escassez de estudos, há relato de dificuldades de conservação (Yamashiro \& Landgraf, 1979) e, complementarmente, observações indicativas da existência de vida curta (Sanchez,1980; Vasconcellos \& Cereda, 1994; Meletti, 1999).

Objetivou-se, portanto, avaliar a influência de diferentes condições de armazenamento na germinação de sementes do maracujádoce.

\section{MATERIALEMÉTODOS}

A experimentação foi realizada no Laboratório de Análise de Sementes do DAMV-UNESP, situada em Botucatu-SP. As sementes de maracujá-doce (Passiflora alata) foram obtidas de frutos maduros provenientes de cultura de primeiro ano, instalada no município de Bandeirantes-PR. Para tanto, frutos em ponto de colheita comercial (início de coloração amarela do epicarpo) foram mantidos na planta por 11 dias adicionais para completar o amadurecimento (coloração totalmente amarela, com tecido coalescendo na região apical). A mucilagem das sementes foi removida em água corrente, através da friccão manual contra peneira de malha plástica. A secagem à sombra ocorreu por um período de três dias, sobre papel absorvente, seguidos de 4 dias adicionais no interior de embalagem de papel. Anteriormente ("sementes frescas" livres da mucilagem com ajuda de tecido de algodão seco) e após a lavagem e secagem, foi realizada a determinação do grau de umidade (estufa $105+$ $3^{\circ} \mathrm{C}$ ) de acordo com Brasil (1992), utilizando-se de quatro amostras de 25 sementes.

Por meio do peso de 100 sementes, selecionadas ao acaso, oito subamostras de 100 sementes foram pesadas com precisão de $0.0001 \mathrm{~g}$ (Brasil, 1992).

Imediatamente após a secagem, as sementes foram armazenadas em: a) embalagem de papel sob condições de laboratório sem controle de temperatura ou de umidade relativa (ambiente não controlado); b) embalagem de papel sob umidade relativa de $40 \%$ sem controle de temperatura; c) embalagem de polietileno (filme duplo com espessura individual de $0,07 \mathrm{~mm}$ ) sob $10^{\circ} \mathrm{C}$ sem controle da umidade relativa (câmara fria).

As sementes foram avaliadas aos zero; $28 ; 56 ; 84 ; 112 ; 168 \mathrm{e}$ 372 dias de armazenamento em relação ao: a) teor de água, utilizando-se de quatro amostras de 25 sementes por tratamento, e; b) teste de germinação, em rolo de papel a 20-30 ${ }^{\circ} \mathrm{C}$ (Osipi, 2000), na ausência de luz, com 50 sementes por repetição previamente tratadas com Thiran $(0,2 \%)$ sendo que as contagens realizadas aos 7; 14; 21 e 28 dias após a semeadura indicaram as plântulas normais e as anormais, assim como as sementes dormentes e as sementes mortas (Brasil, 1992). Na última contagem, o aspecto do tegumento das sementes dormentes foi observado para constatar se estavam ou não vivas.

Os dados de germinação foram submetidos à análise da variância, em delineamento inteiramente ao acaso, no esquema fatorial $3 \times 7$ (condições de armazenamento x períodos de armazenagem), com quatro repetições, e as médias comparadas através do teste de Tukey $(5 \%)$.

\section{RESULTADOSE DISCUSSÃO}

No início do experimento, as sementes frescas apresentavamse com $18 \%$ de teor de água, e as secas com $10 \%$ de teor de água, $80 \%$ de germinação (plântulas normais), 3,5\% de plântulas anormais, 14,0\% de sementes dormentes e $2,0 \%$ de sementes mortas. O peso de 100 sementes foi 3,8 $\mathrm{g}$ (Brasil, 1992).

Verifica-se que o efeito da interação tempo e condições de armazenamento foi significativo ao nível de 5\% de probabilidade, para porcentagem de sementes que germinaram originando plântulas normais e anormais. Também ocorreu interação significativa entre ambientes e períodos de armazenamento, para a característica teor de água das sementes.

\footnotetext{
${ }^{1}$ (Trabalho 097/2004). Recebido: 03/08/2004. Aceito para publicação:19/04/2005. Parte integrante da tese de doutorado do $1^{\circ}$ autor.

${ }^{2}$ Eng $^{\mathrm{a}}$ Agr $^{\mathrm{a}}$. Prof ${ }^{\mathrm{a}}$. Doutora - FALM, CP.261, 86360-000-Bandeirantes-PR, Brasil. elisete @ ffalm.br - Bolsista CAPES.

${ }^{3}$ Eng $^{\circ}$. Agr ${ }^{\circ}$. Prof ${ }^{\circ}$. Titular Aposentado/Voluntário do DPV, FCA- Botucatu- UNESP.18603-970- Botucatu-SP. secdamv@ @fca.unesp.br Bolsista CNPq.
} 
TABELA 1 - Teor de água (\%) proveniente de sementes do maracujá-doce armazenadas em condições de ambiente não controlado, câmara fria e câmara seca.

\begin{tabular}{|c|c|c|c|c|c|c|c|}
\hline \multirow{2}{*}{ Condições } & \multicolumn{7}{|c|}{ Dias de Armazenamento } \\
\hline & 0 & 28 & 56 & 84 & 112 & 168 & 372 \\
\hline N. Contr. & $10,0 \mathrm{~A} \mathrm{a}$ & $8,9 \mathrm{~B} \mathrm{~b}$ & $8,6 \mathrm{~B} \mathrm{c}$ & $8,3 \mathrm{~B} \mathrm{~d}$ & $8,6 \mathrm{~B} \mathrm{c}$ & $8,2 \mathrm{~B} \mathrm{~d}$ & $7,7 \mathrm{~B} \mathrm{e}$ \\
\hline C. Fria & $10,0 \mathrm{Ad}$ & $10,1 \mathrm{~A} \mathrm{~cd}$ & $10,3 \mathrm{~A} \mathrm{bc}$ & $10,1 \mathrm{~A} \mathrm{~cd}$ & $10,3 \mathrm{~A} \mathrm{bc}$ & $10,5 \mathrm{~A} \mathrm{~b}$ & $11,0 \mathrm{Aa}$ \\
\hline C. Seca & $10,0 \mathrm{~A} \mathrm{a}$ & $6,2 \mathrm{C} \mathrm{c}$ & $5,8 \mathrm{C} \mathrm{d}$ & $6,5 \mathrm{C} \mathrm{b}$ & $5,2 \mathrm{C} \mathrm{e}$ & $5,3 \mathrm{C} \mathrm{e}$ & $5,8 \mathrm{C} \mathrm{d}$ \\
\hline \multirow{3}{*}{\multicolumn{2}{|c|}{$\begin{array}{l}\text { D.M.S.5\% (Condições) } \\
\text { D.M.S.5\% (Dias de Armaz.) } \\
\text { C.V.(\%) }\end{array}$}} & 0,20 & & & & & \\
\hline & & 0,25 & & & & & \\
\hline & & 1,36 & & & & & \\
\hline
\end{tabular}

Médias seguidas de mesma letra maiúscula nas colunas não diferem pelo teste de Tukey $(\mathrm{P}>0,05)$.

Médias seguidas de mesma letra minúscula nas linhas não diferem pelo teste de Tukey $(\mathrm{P}>0,05)$

TABELA 2 - Porcentagens de plântulas normais provenientes de sementes de maracujá-doce armazenadas em condições de ambiente não controlado, câmara fria e câmara seca.

\begin{tabular}{|c|c|c|c|c|c|c|c|}
\hline Condições & \multicolumn{7}{|c|}{ Dias de Armazenamento } \\
\hline C. Fria & $80,5 \mathrm{~A} \mathrm{ab}$ & $82,5 \mathrm{~A} \mathrm{a}$ & $62,0 \mathrm{~A} \mathrm{c}$ & $76,5 \mathrm{~A} a b c$ & $77,5 \mathrm{~A}$ abc & $78,0 \mathrm{~A} \mathrm{ab}$ & $65,5 \mathrm{~A}$ bc \\
\hline \multicolumn{3}{|c|}{ D.M.S. 5\% (Condições) } & 12,32 & & & & \\
\hline \multicolumn{3}{|c|}{ D.M.S. 5\% (Dias de Armazenamento) } & 15,62 & & & & \\
\hline \multicolumn{3}{|l|}{ C.V. $(\%)$} & 10,26 & & & & \\
\hline
\end{tabular}

Médias seguidas de mesma letra maiúscula nas colunas não diferem pelo teste de Tukey $(\mathrm{P}>0,05)$.

Médias seguidas de mesma letra minúscula nas linhas não diferem pelo teste de Tukey $(\mathrm{P}>0,05)$

No decorrer de todo o período de armazenamento, o teor de água das sementes diferiu entre os três ambientes (Tabela 1). Comportamento similar em sementes do maracujá-amarelo armazenadas em ambientes semelhantes foi obtido por Nakagawa et al. (1991).

Verifica-se que os ambientes em que as sementes ficaram armazenadas, não exerceram influência sobre a germinação nos diferentes períodos de conservação até 168 dias (Tabela 2). Este fato discorda do observado por São José (1987) ao final de seis meses em maracujáamarelo, o qual constatou germinação superior em sementes conservadas em ambiente não controlado em relação ao refrigerado. Já Almeida (1985) verificou, seis meses após armazenamento em três diferentes ambientes, a não-influência dos mesmos, mas constatou o aumento da porcentagem de germinação de sementes de maracujá-amarelo, em relação à inicial (sem armazenamento).

Todavia, os dados obtidos diferem dos resultados de Sanchez (1980), o qual obteve porcentagem de germinação baixa variando de 4 a $5 \%$ e de zero a $1 \%$ após conservar sementes de maracujá-doce por seis meses, em ambiente não controlado e refrigerado, respectivamente. Esses resultados, possivelmente, não decorreram somente das condições e/ ou tempo de conservação, uma vez que as porcentagens iniciais, anteriores ao armazenamento, também eram baixas (14\% a 22\%). Outros problemas poderiam estar envolvidos para a obtenção desses resultados, como a utilização de temperatura constante nos testes de laboratório e/ ou o grau de maturidade não adequado dos frutos, como foi verificado por Osipi (2000).

Por outro lado, a redução da porcentagem de germinação durante o período de armazenamento em ambiente não controlado (Tabela 2) concorda com as observações feitas por Vasconcellos \& Cereda (1994), Yamashiro \& Landgraf (1979) e Meletti (1999), relatando curta viabilidade das sementes dessa espécie.

Nos resultados obtidos, não se constatou aumento na germinação das sementes após um período inicial de armazenamento em ambiente não controlado (Tabela 2), como foi verificado para o maracujáamarelo (Almeida, 1985; São José, 1987; Nakagawa et al., 1991) e Passiflora giberti (Melo et al., 1998), devido à perda de dormência apresentada pelas sementes.

Para um período mais prolongado, de 372 dias (aproximadamente 12 meses), constatou-se que as três condições de armazenamento afetaram a porcentagem de germinação de forma diferenciada (Tabela 2), apresentando a maior porcentagem, a condição de armazenamento em câmara fria, seguida de câmara seca, e a menor em ambiente não controlado, o que está de acordo com resultados obtidos para o maracujáamarelo (Almeida, 1985; Nakagawa et al.,1991), sendo que Almeida (1985) constatou diferenças não significativas entre os ambientes controlados.

Verifica-se que houve melhor conservação das sementes (Tabela 2) na câmara fria $(65,5 \%)$, do que na câmara seca $(52,0 \%)$, mas ambas as condições proporcionaram porcentagem de germinação superior a $50 \%$, aos 12 meses de armazenamento, o mesmo não ocorrendo para o ambiente não controlado $(31,5 \%)$. Esses resultados demonstram a possibilidade de conservação por mais de 12 meses em ambiente de câmara fria. Fonseca (2004) armazenou sementes de maracujá-amarelo a $10^{\circ} \mathrm{C}$ durante 365 dias e obteve $99 \%$ de germinação. Nakagawa et al. (1991) obtiveram para

TABELA 3 - Porcentagens de plântulas anormais provenientes de sementes de maracujá-doce armazenadas em condições de ambiente não controlado, câmara fria e câmara seca.

\begin{tabular}{lcccrcrc}
\hline \multirow{2}{*}{ Condições } & \multicolumn{7}{c}{ Dias de Armazenamento } \\
\cline { 2 - 7 } & $\mathbf{0}$ & $\mathbf{2 8}$ & $\mathbf{5 6}$ & $\mathbf{8 4}$ & $\mathbf{1 1 2}$ & $\mathbf{1 6 8}$ & $\mathbf{3 7 2}$ \\
\hline N. Contr. & $3,5 \mathrm{~A} \mathrm{~d}$ & $6,0 \mathrm{~A} \mathrm{~cd}$ & $10,5 \mathrm{~A} \mathrm{bcd}$ & $10,5 \mathrm{~A} \mathrm{bcd}$ & $13,0 \mathrm{~A} \mathrm{bc}$ & $15,5 \mathrm{~A} \mathrm{~b}$ & $54,0 \mathrm{~A} \mathrm{a}$ \\
C. Fria & $3,5 \mathrm{~A} \mathrm{c}$ & $5,0 \mathrm{~A} \mathrm{bc}$ & $12,5 \mathrm{~A} \mathrm{ab}$ & $7,5 \mathrm{~A} \mathrm{abc}$ & $8,0 \mathrm{~A} \mathrm{abc}$ & $4,0 \mathrm{~B} \mathrm{bc}$ & $15,5 \mathrm{~B} \mathrm{a}$ \\
C. Seca & $3,5 \mathrm{~A} \mathrm{c}$ & $4,0 \mathrm{~A} \mathrm{c}$ & $16,5 \mathrm{~A} \mathrm{ab}$ & $10,5 \mathrm{~A} \mathrm{bc}$ & $8,5 \mathrm{~A} \mathrm{bc}$ & $5,0 \mathrm{~B} \mathrm{c}$ & $22,0 \mathrm{~B} \mathrm{a}$ \\
\hline D.M.S. 5\% (Condições) & & & & \\
D.M.S. 5\% (Dias de Armazenamento) & 8,04 & & \\
C.V.(\%) & & 36,41 & &
\end{tabular}

Médias seguidas de mesma letra maiúscula nas colunas não diferem pelo teste de Tukey ( $\mathrm{P}>0,05)$.

Médias seguidas de mesma letra minúscula nas linhas não diferem pelo teste de Tukey $(P>0,05)$ 
sementes do maracujá-amarelo, nos respectivos ambientes anteriormente mencionados, porcentagens semelhantes às citadas aos 57 meses de armazenamento. Já Almeida (1985) obteve, após 12 meses de armazenamento, $82 \%$ para câmara seca e $63 \%$ para câmara fria, em frutos de maracujá-amarelo com 77 dias de idade (pós antese), São José (1987), embora tenha constatado melhor conservação da qualidade fisiológica da semente armazenada por 12 meses em condições de refrigerador, não obteve diferença na porcentagem de germinação com relação ao ambiente não controlado, para o mesmo período.

De acordo com Nakagawa et al. (1991), os resultados obtidos em suas investigações reforçaram a caracterização das sementes do maracujá-amarelo como ortodoxas, anteriormente referida por Becwer et al. (1983). Portanto, a similaridade dos resultados desta pesquisa com os de Nakagawa et al. (1991), indica a mesma característica para as sementes do maracujá-doce.

O comportamento observado para as plântulas anormais (Tabela 3 ) se repetiu dentro de cada período de armazenamento até 112 dias nas três condições estudadas. A partir de 168 dias, o ambiente não controlado apresentou maior porcentagem de plântulas anormais, do que as condições de câmara fria e câmara seca, não havendo diferença significativa entre estas. Isto indica que, em condições não controladas de ambiente, houve maior deterioração das sementes, ocasionando a presença de maior quantidade de plântulas anormais. As porcentagens de sementes dormentes e mortas foram afetadas pelo tempo de armazenamento (Tabela 4). As sementes mortas não diferiram em função dos ambientes de conservação. Já as sementes dormentes apresentaram maior porcentagem na câmara seca do que no ambiente não controlado.

TABELA 4 - Porcentagens de sementes dormentes e mortas verificadas durante o armazenamento de sementes de maracujá-doce em condições de ambiente não controlado, câmara fria e câmara seca.

\begin{tabular}{|c|c|c|}
\hline Condições & Dormentes & Mortas \\
\hline Não Controlado & $15,1 \quad \mathrm{~B}$ & $0,71 \mathrm{~A}$ \\
\hline Câmara Fria & $16,4 \quad \mathrm{AB}$ & $0,36 \mathrm{~A}$ \\
\hline Câmara Seca & 20,3 A & $0,57 \mathrm{~A}$ \\
\hline $\operatorname{DMS}(5 \%)$ & 3,95 & 12,32 \\
\hline C.V. $(\%)$ & 35,59 & 159,39 \\
\hline Dias de Armazenamento & Dormentes & Mortas \\
\hline 0 & $14,0 \mathrm{~B}$ & $2,0 \mathrm{~A}$ \\
\hline 28 & $13,0 \mathrm{~B}$ & $1,2 \mathrm{AB}$ \\
\hline 56 & $22,0 \quad \mathrm{~A}$ & $0,3 \mathrm{BC}$ \\
\hline 84 & $16,8 \quad \mathrm{AB}$ & $0.0 \mathrm{C}$ \\
\hline 112 & $18.2 \mathrm{AB}$ & $0,3 \mathrm{BC}$ \\
\hline 168 & $17,2 \mathrm{AB}$ & $0.0 \mathrm{C}$ \\
\hline 372 & $19.8 \mathrm{AB}$ & $0.0 \mathrm{C}$ \\
\hline $\operatorname{DMS}(5 \%)$ & 7,66 & 1,09 \\
\hline C.V. $(\%)$ & 35,59 & 159,4 \\
\hline
\end{tabular}

Médias seguidas de mesma letra ,na vertical, não diferem pelo teste de Tukey $(\mathrm{P}>0,05)$.

\section{CONCLUSÕES}

A germinação não difere entre os ambientes de conservação durante os seis meses iniciais de armazenamento. Após doze meses, contudo, a conservação é favorecida em sementes com grau de umidade próximo a $10 \%$, embaladas em sacos de polietileno e mantidas a $10^{\circ} \mathrm{C}$.

\section{REFERÊNCIAS}

ALMEIDA, A.M. Maturação e qualidade fisiológica de sementes de maracujá amarelo (Passiflora edulis f. flavicarpa Deg.). 1985. 91f. Dissertação (Mestrado em Agronomia)-Faculdade de Ciências Agronômicas, Universidade Estadual Paulista, Botucatu, 1985.

BECWER, M.R.; STANWOOD, P.C.; LEONHARDT, K.W. Dehydration effects on freezing characteristics and survival in liquid nitrogen of desiccation-tolerant and desiccation-sensitive seeds. Journal of the American Society for Horticultural Science, Alexandria, v.108, n.4, p.6138-8, 1983.

BRASIL. Ministério da Agricultura. Regras para análise de sementes. Brasília, 1992.p.365.

FONSECA, S.C.L. Conservação de sementes de maracujá-amarelo (Passiflora edulis f. flavicarpa): interferência do teor de água das sementes e da temperatura do ambiente, 2004. 32f. Tese (Doutorado em Agronomia) - Escola Superior de Agricultura Luiz de Queiroz, Universidade de São Paulo, Piracicaba, 2004.

GERALDI JÚNIOR, G. Estudo da germinação de sementes de maracujáamarelo (Passiflora edulis Sims f. flavicarpa Deg.) armazenadas sob duas diferentes condições. 1974. 26f. Monografia (Trabalho de Graduação em Agronomia) - Faculdade de Ciências Agrárias e Veterinárias, Universidade Estadual Paulista, Jaboticabal, 1974.

MELETTI, L. M. M. Situação regional da cultura do maracujá - sudesteEstado de São Paulo. In: REUNIÃO TÉCNICA DE PESQUISA EM MARACUJAZEIRO, 2., 1999, Londrina. Resumos... Londrina: IAPAR/RBF, 1999. p.15-9.

MELO,A.L.; PENÁRIO, R.; SADER, R.; OLIVEIRA, J.C. Comportamento germinativo de espécies de maracujá. Jaboticabal:Faculdade de Ciências Agrárias e Veterinárias, UNESP, 1998. 8p.

NAKAGAWA, J.; CAVARIANI, C.; AMARAL, W.A.N. do. Armazenamento de sementes de maracujá-amarelo. Revista Brasileira de Sementes, Brasília, v.13, n.1, p.76-80, 1991.

OSIPI, E. A. F. Efeito da temperatura, da maturação do fruto e do armazenamento na qualidade fisiológica de sementes de maracujádoce (Passiflora alata Dryander), 2000. 98f. Tese (Doutorado em Agronomia) - Faculdade de Ciências Agronômicas, Universidade Estadual Paulista, Botucatu, 2000.

SANCHEZ, S.V. Influência de tipos de degomagem e armazenamento sobre a germinação de sementes e estudo sobre a quebra de dormência de maracujá-doce (Passiflora alata Ait). 1980. $21 \mathrm{f}$. Monografia (Trabalho de Graduação em Agronomia) - Faculdade de Ciências Agrárias e Veterinárias, Universidade Estadual Paulista, Jaboticabal, 1980. 01p. (Monografia).

SÃO JOSÉ, A. R. Influência do método de extração na qualidade fisiológica de sementes de maracujazeiro-amarelo (P. edulis Sims. f. flavicarpa Deg). 1987. 87f. Dissertação (Mestrado em Agronomia/ Horticultura)- Faculdade de Ciências Agronômicas, Universidade Estadual Paulista, Botucatu, 1987.

THAI, Y.T. Storage of passion fruit (Passiflora edulis f. flavicarpa) seeds. Malaysian Agricultural Journal, Kuola Lumpur, v.51, n.1, p.118-23, 1977.

VASCONCELLOS, M.A.S.; CEREDA, E. O cultivo do maracujá-doce. In: SÃO JOSÉ, A.R. Maracujá, Produção e Mercado. Vitória da Conquista: DFZ/UESB, 1994. p.71-83.

YAMASHIRO, T.; LANDGRAF, J.H. Maracujá-açu (P. alata Ait): portaenxerto resistente à fusariose do maracujazeiro (P. edulis f. flavicarpa Deg.). In: CONGRESSO BRASILEIRODEFRUTICULTURA, 5., 1979, Pelotas. Anais... Pelotas: SBF, 1979. p.918-21. 